\title{
Lógicas productivas y empresa colonial desde la historia cultural. El caso del ingenio San Nicolás Tolentino, Nueva España, finales del siglo XVII
}

\author{
Alejandra Araya Espinoza \\ Universidad de Chile \\ alearaya@hotmail.com
}

\begin{abstract}
Resumen $^{1}$
Este trabajo se basa en el análisis cualitativo de los datos contenidos en los libros de cuentas del ingenio San Nicolás Tolentino, México, correspondientes al año 1694. Si bien el análisis se realiza desde los temas clásicos de la historia socioeconómica, como los sistemas de trabajo, pretende abordar las lógicas productivas de una empresa colonial desde la historia cultural. La mano de obra es un recurso escaso en el siglo XVII tanto por las restricciones legales a su uso como por la desestructuración demográfica de la población indígena, lo que obliga a planear ingeniosamente su obtención, incluyendo lo que hoy se llamaría política cultural asociada al consumo, tendiente a crear una jerarquía social y un nuevo régimen de relaciones sociales de acuerdo con nuevos modos de producción.
\end{abstract}

Palabras clave: HISTORIA CULTURAL, EMPRESAS COLONIALES, INGENIO, NUEVA ESPAÑA, SIGLO XVII.

\begin{abstract}
This paper is based on the qualitative analyses of the data contained in the libros de cuentas, Ingenio San Nicolás Tolentino, México, in 1694. The present analyses, if is based on the classical perspective of the social and economic history (as in work system perspective), is used in order to discuss the productive logic of a colonial enterprise from cultural history perspective. The labor force was a scarce resource in the seventeenth century, given the legal restrictions to handle in the demographic destructuring of the native population. These obstacles required the creation of creative methods to obtain the labor force, including that wich we would now call a cultural
\end{abstract}

1 Este trabajo fue realizado, en una primera versión, en el seminario de historia económica colonial dictado por el doctor Carlos Sempat Assadourian en el programa de Doctorado en Historia, de El Colegio de México, cuyos comentarios agradezco. 
policy associated with consumption, in order to create a social hierarchy and a new regime of social relationships, constructed according to new production modes.

Key words: CULTURAL HISTORY, COLONIAL ENTERPRISE, INGENIO, NUEVA ESPAÑA, $17^{\mathrm{TH}}$ CENTURY.

En 14 del dicho mes se le dieron al padre prior de Santo

Domingo del pueblo de Izúcar 6 panes de azúcar por razón de Pascuas y por lo que suele intervenir con los indios de aquel pueblo en que tal vez den su agua a este Ingenio de noche ${ }^{2}$.

Este trabajo se basa en el análisis cualitativo de los datos contenidos en los libros de cuentas del ingenio San Nicolás Tolentino, en Izúcar, correspondiente al año de 1694. Las memorias de gastos reunidas en 14 expedientes, con motivo del traspaso del ingenio a otro dueño, forman parte de una suerte de auditoría. Este tipo de registros comienza a ser frecuente a finales del siglo XVII como expresión concreta de lógicas más racionales de producción centradas, principalmente, en el cálculo de costos. Los expedientes reúnen tres tipos de memorias de gastos, unas referidas a insumos de operación, como el alimento de los trabajadores, otras a herramientas con registro diario y libros de ventas del azúcar, y las de gastos en el pago de los trabajadores, que dan cuenta y razón de los salarios por día, ajustadas al mes o anualmente. En estos últimos se incluye, en nota aparte, lo que corresponde a los esclavos y esclavas del ingenio. Estos expedientes se encuentran en el Archivo General de la Nación de México, constituyendo un fondo en sí mismo, el Concurso de Calvo, que contiene información desde 1694 hasta 1695. En este trabajo se ha utilizado solo la concerniente a 1694, por ser la más completa, continua y sistemática en sus registros. La información extraída aporta a los estudios sobre productividad y gastos en las empresas coloniales; en este caso, referida a la política de contratación de mano de obra, régimen de trabajo y mecanismos de mantenimiento de la mano de obra de acuerdo con lógicas de gasto. Temas clásicos de la historia social y del trabajo se abordan aquí, como el de la esclavitud, la servidumbre y el peonaje, así como el funcionamiento de los sistemas de pago asalariados o no asalariados. Sin embargo, la perspectiva de análisis no se sitúa en la discusión sobre el funcionamiento del sistema capitalista en América a partir de los sistemas de trabajo, sino que usa los modos de contratación y uso de la mano de obra para caracterizar el tipo de lógica productiva de una empresa colonial desde la historia cultural. La propia información de las memorias de gastos y las de cuenta y razón ponen de relieve la necesidad de centrar los análisis económicos en los aspectos socioculturales de la vida económica que conectan la producción con el consumo. En este caso, las lógicas de gasto y consumo de la población permanente de

2 "Cuenta de los panes de azúcar que se han gastado en el gasto ordinario en la casa del Ingenio, rasiones, dados, conservas, en alfeñiquez y que se han vendido este año de 1694”, Archivo General de la Nación -en adelante AGN- (México), Concurso de Calvo, vol. I, fol. 360. 
una empresa azucarera que, dadas sus características particulares dentro de las empresas agrícolas coloniales, requiere una población estable que la haga funcionar, pues de ella depende el éxito de la empresa. La mano de obra es un recurso escaso en el siglo XVII, tanto por las restricciones legales a su uso como por la desestructuración demográfica de la población indígena, lo que obliga a planear ingeniosamente su obtención, incluyendo lo que hoy se llamaría política cultural asociada al consumo tendiente a crear una jerarquía social y un nuevo régimen de relaciones en torno a nuevos modos de producción. La constitución de mercados de consumo en y alrededor de la empresa exige dar cuenta de cómo el clásico tema de la "deuda” peonal o la servidumbre por deudas puede ser entendido también, según el caso, como una inversión a futuro creando mercados de consumo obligado, a cambio de estatus en un nuevo orden: una sociedad colonial. Ese nuevo orden de cosas también implica el uso del salario por los indios libres, como mecanismo de satisfacción de sus necesidades cuando el autoabastecimiento ya no es posible. La introducción de los hábitos de consumo no requiere, necesariamente, de monetarización fraccionada, pero estos son esenciales para la potencial consolidación de un mercado interno de consumo basado en el salario a nivel simbólico.

\section{La empresa azucarera como sector “moderno”: el cálculo económico en una sociedad colonial}

El ingenio San Nicolás Tolentino pertenecía al orden de las empresas coloniales más “modernas” del siglo XVII. La historiografía del azúcar coincide en calificar a este sector de los ingenios como verdadero centro de producción y experimentación, al ser la caña un cultivo encadenado a múltiples procesos para llegar a ser azúcar. Para Beatriz Scharrer, siembras, edificios, maquinarias, instalaciones, trabajadores, animales, insumos y conocimientos tenían que ser coordinados cual si se tratara de una línea de producción del siglo XX ${ }^{3}$. Y en opinión de Horacio Crespo, la producción de azúcar era un "complejo económico”, al distinguir dos sectores como el campo y la fábrica, pero agregando un tercero de importancia y "autonomía” desconocida dentro de otro tipo de empresas agrícolas o agroindustriales coloniales de los siglos XVI y XVII: la administración y el control de la producción. El proceso de elaboración del azúcar hizo que la contabilidad en las haciendas cañeras y asociadas se desarrollara y perfeccionara, puesto que la encadenación de varias esferas económicas hizo indispensable calcular los costos de cada uno de los involucrados para poder fusionar de manera eficaz el agro, y sus tiempos, con la fabricación de azúcar y las demandas del mercado ${ }^{4}$.

Beatriz Scharrer Tamm, Azúcar y trabajo. Tecnología de los siglos XVII y XVIII en el actual estado de Morelos (México: Ciesas; Instituto de Cultura de Morelos, 1997).

4 Horacio Crespo, Historia del azúcar en México, 2 vols. (México: Fondo de Cultura Económica; Azúcar S. A. de C. V., 1980-1990). 
Para entender la novedad y singularidad de este tipo de empresas en el contexto colonial, pensemos en la lógica o racionalidad que anima las decisiones de las mismas, las bases del cálculo económico. Para este ejercicio he tomado un año de los libros de cuentas del ingenio San Nicolás Tolentino, centrándome en las cuentas de gastos en salarios de sirvientes y en las cuentas del gasto diario. La lógica del cálculo económico remite a la cuestión de si la empresa corresponde a un modelo capitalista de explotación o de "sector comercializado" o a un "sector natural", en términos de Witold $\mathrm{Kula}^{5}$. Me parece interesante centrar el ejercicio en los motivos y orientaciones de la actividad del sujeto económico más que en los resultados objetivos del cálculo, ya que esto supone tener una serie de datos más completa que permita comparar los productos elaborados con la suma de los bienes empleados en la producción, lo que también exige disponer de información de los precios de mercado de cada uno de esos bienes. Si la empresa azucarera del siglo XVII corresponde a un modelo de economía capitalista o a uno de tipo natural es un asunto que debe pensarse en la especifidad de la economía colonial americana; en otras palabras, la cuestión es cuál era la "modernidad” del sector dentro de esa economía.

La particularidad de las empresas azucareras venía de la aplicación de un cálculo racional a la producción, que a fines del XVII solo implicaba mayor eficacia en el uso de los recursos disponibles. Como la base de la empresa era la tierra destinada al cultivo de la materia prima, la racionalización partió por ella. Para que la explotación de la tierra sea considerada una empresa debe haber una estrecha relación entre racionalidad, tecnología y productividad. En este proceso hay varias etapas, las cuales dependen de la lógica del cálculo económico. El concepto de latifundio es útil para entrar en el tema de las decisiones del ingenio a fines del XVII. Rolando Mellafe definió el latifundio como

[...] unidad unipersonal relativamente extensa que constituye una unidad económica y social con algún grado de racionalización de la producción y que tiende a ser excluyente respecto a la distribución productiva y al uso de los recursos agrarios. Está bajo constantes presiones de carácter demográfico y político y muestra agresividad ante los frentes adversos ${ }^{6}$.

La producción azucarera, en el proceso de constitución de haciendas dedicadas a la explotación de ese recurso, enfrentó frentes adversos que tuvieron que ver con el acceso a fuentes permanentes de agua indispensables para el tipo de cultivo, y con la disponibilidad de grandes extensiones de tierra necesarias tanto para el cultivo de caña como para la crianza de ganado, necesario para las labores del trapiche o inge-

Witold Kula, Teoría económica del sistema feudal, 2 ed. (México: Siglo XXI, 1979).

6 Rolando Mellafe Rojas, “Latifundio y poder rural en Chile de los siglos XVII y XVIII”, en Historia Social de Chile y América. Sugerencias y aproximaciones (Santiago: Editorial Universitaria, 1986), 88-89. 
nio, y con la mano de obra aplicada al cultivo y procesamiento de la caña durante todo el año. Me centraré en el último punto, pero veré a grandes rasgos algunos aspectos de los dos anteriores.

El valle que rodea la ciudad de Izúcar es el más amplio de la zona, con 116 km²; otros valles son Santa Ana Necoxtla, San Miguel Ayotla y Tepeojuma en torno a Chietla. El clima es tropical de sabana, lluvioso, con cinco a seis meses húmedos (fines de marzo a principios de octubre), lo que posibilitó la introducción del cultivo de la caña desde mediados del siglo XVI, aunque no era la producción predominante. Izúcar era un centro urbano prehispánico que contaba con una red de comunicación y de riego muy sofisticada. Tanto las condiciones climáticas como las tecnologías agrícolas hicieron del valle un lugar privilegiado por cuanto se podía cultivar con sistemas tanto de riego y humedad como de temporal. Varios autores coinciden en que el protagonista de la historia de la agricultura regional al sur de ciudad de México, desde el último cuarto del siglo XVI, fue el azúcar. Y el valle de Izúcar fue la unidad de producción más importante de la región de Atlixco, activadora de cruciales cambios tecnológicos y sociales en la sociedad indígena. Desde 1572 destacaron tres zonas azucareras: el norte y oriente de Tepeojuma, Chietla-Ahuehuecingo y el sur del valle de Izúcar, donde se situaron los ingenios de San Juan Bautista Atotonilco, de Antonio de Herrera y de Marcos Pérez, llamado San Nicolás Tolentino, cerca de Matzaco y Ayutla 7 .

En 1622, San Nicolás Tolentino era considerado solo como un trapiche y contaba con un surco de agua. Pero para 1635 ya pagaba 2.000 ducados por ocho surcos y era llamado "hacienda", puesto que poseía 20 caballerías de tierra, tres sitios de ganado menor con 12 mil cabezas de ovejas grandes y chicas, y dos sitios de ganado mayor con vacas, toros, bueyes; una hacienda adjunta con casas, corrales, 200 cabezas de ganado mayor y 350 cabras, una merced para plantar caña y un "cacicazgo que le está agregado"; sembradíos de garbanzo, chile; aperos y derecho a indios gañanes. En 1646, estaba totalmente dedicado al cultivo de caña y a la molienda con 41 caballerías de caña, extendiéndose la propiedad hacia los terrenos de los indios de San Lucas Cuilocán ${ }^{8}$. Para 1694, año que nos ocupa, no tenemos información sobre la extensión de la propiedad, pero el libro de cuentas indica que poseía dos haciendas adjuntas, la Estancia de Nopala y el Rancho del Rosario, dedicadas al cultivo de maíz, frijoles y garbanzos para surtir las raciones de los trabajadores. La segunda contaba con bosques, de los cuales se sacaba la madera para alimentar las calderas del ingenio, hacer los ranchos de trabajadores y las instalaciones, fabricar las piezas del trapiche, vigas y bateas. Junto a ellas, la vaquería de Xaltianguez donde se reproducía el ganado para el funcionamiento del trapiche, que utilizaba 184 bueyes al año. En el libro de las

7 Carlos Paredes Martínez, El impacto de la conquista y colonización española en la antigua Coatlalpán (Izúcar, Puebla) en el primer siglo colonial, Cuadernos de la Casa Chata (México: Ciesas, 1991), 60-63.

8 Información proveniente de AGN (México), Tierras, vol. 95, exp. 2, fols. 9 y ss., citado en Ibídem, 63. 
Figura 1

Ubicación de la zona Puebla-Tlaxcala en México

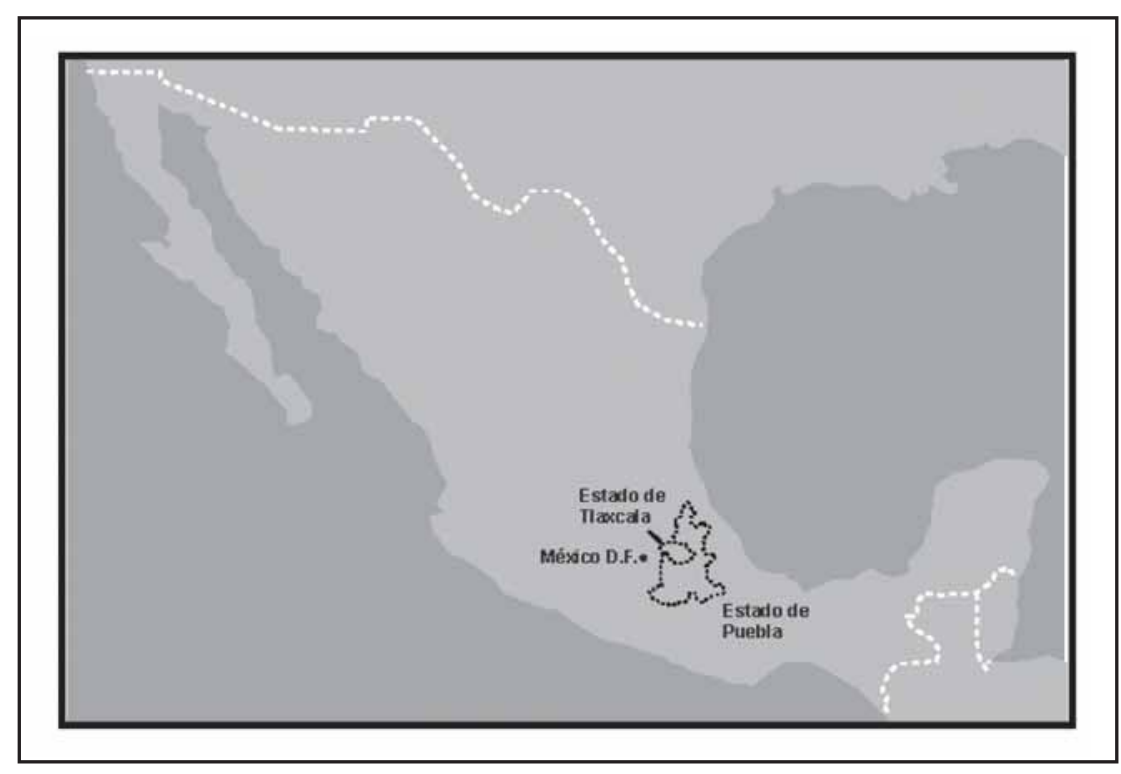

Figura 2

Ubicación del ingenio San Nicolás Tolentino en el valle de Atlixco

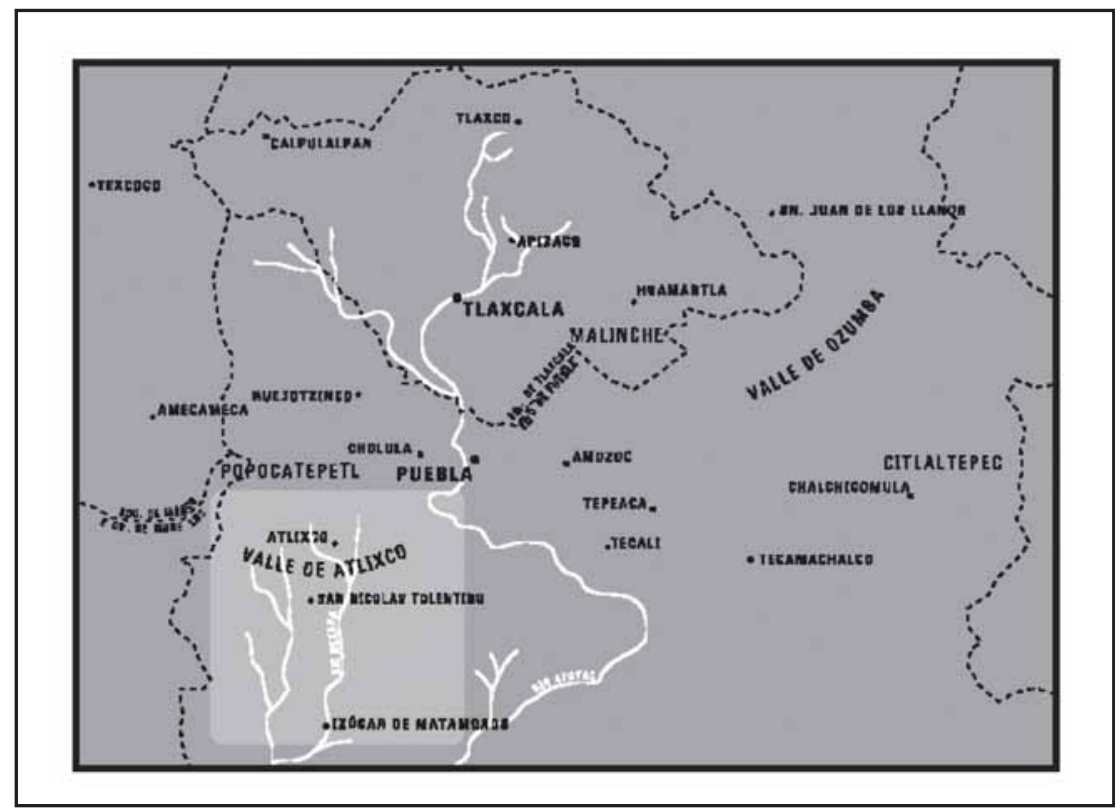

Fuente: Croquis simplificados tomados de los mapas que presenta Herbert J. Nickel, Morfología social de la hacienda mexicana (México: FCE, 1996), 184 y 185. 
raciones se menciona carne de vaca y carnero, por lo que en alguna de estas propiedades debió criarse ganado para alimento así como mulas para el transporte de azúcar refinada hacia los centros de consumo. Contaba con 113 esclavos entre hombres, mujeres y muchachos, necesitando alrededor de 40 sirvientes permanentes en el año y la fuerza de 29.964 indios de cuadrillas para cubrir la cadena de producción del azúcar.

El proceso de expansión de la hacienda fue evidente, en relación con los insumos requeridos para el funcionamiento del ingenio, ahora ya como "fábrica de hacer azúcar". En este sentido, también se puede ver una conexión entre este proceso y la política de congregación de pueblos en el siglo XVI en la zona. Esta tuvo por objeto reubicar la población para su mejor aprovechamiento como mano de obra, pero también despejar las tierras que necesitaba el nuevo cultivo, por cuanto coincide con el período de intensificación del cultivo de caña de azúcar. Entre 1603 y 1620 se llevaron a cabo cinco congregaciones en el valle: las de Epatlán, Matzaco, Tepapayeca, Cueztpala, Tatetla y Cuilocán ${ }^{9}$ Junto a la necesidad de expansión territorial para cultivo y cría de ganado, entre cuyos mecanismos encontramos el arrendamiento de terrenos de indios, la compra y la reclamación de terrenos baldíos, estaba el de la obtención del agua necesaria para el cultivo de la caña, motivo que aumentaba la presión sobre la tierra y, específicamente, sobre los terrenos que tenían acceso al líquido con más facilidad o que se interponían entre las fuentes de agua y la hacienda. Carlos Paredes Martínez señala que las nuevas exigencias de agua fueron motivo de muchos pleitos entre el pueblo de Izúcar y los agricultores españoles en general. Indica que para 1622 la población india de Izúcar se quejaba ante las autoridades por la sustracción de agua del río Nexapa por parte de los españoles, ya que, situados al sur del valle, no la recibían a pesar de ser un río de agua permanente ${ }^{10}$.

Quizás, a fines del siglo XVII, el aprovisionamiento seguía siendo el gran problema para el cultivo por cuanto vemos, en la cita inicial de este texto, que dentro de las preocupaciones del ingenio está el conseguir agua para riego nocturno llevando a cabo negociaciones con los indios del pueblo de Izúcar a través del presbítero del convento de Santo Domingo. Posiblemente alguna legislación protegía el agua para los indios del pueblo, razón por la cual se necesitaba un intermediario y el consentimiento de los indios para hacer uso de ella en forma extraordinaria. Esto es, una presión sobre el recurso que implicó negociaciones con distintos actores, incluyendo a la Iglesia. El ingenio también invirtió 25 pesos para pagar a los indios de Cuilocán la confección de atarjales, y varios trabajadores de la hacienda se ocupaban en la reparación de los jagüeyes ${ }^{11}$.

9 Ibídem, 30. También, para el tema del agua y la constitución del latifundio, véase Gisela von Wobeser, La formación de la hacienda en la época colonial. El uso de la tierra y el agua (México: UNAM, 1989).

10 Carlos Paredes Martínez, La región de Atlixco, Huaquechula y Tochimilco. La sociedad y la agricultura en el siglo XVI (México: Fondo de Cultura Económica; Ciesas, 1991), 90.

11 "Memoria del gasto ordinario que se ha hecho en este ingenio de San Nicolás Tolentino desde $1^{\circ}$ de enero de 1694 hasta fin de diciembre del, por sus días y meses”, AGN, Concurso de Calvo, vol. I, exp.7, fols. 216-257v, 240v. 
A fines del siglo XVII, el ingenio San Nicolás Tolentino constituía un polo regional de desarrollo. Había logrado consolidarse exitosamente haciendo frente a la competencia por obtener recursos por parte de la producción triguera predominante en la región, incluso favorecida por una política virreinal tendiente a asegurar el abastecimiento de la ciudad de México. El ingenio generó un complejo sistema de relaciones económicas que vinculaba pueblos de indios, villas de españoles y la ciudad de México. Esto supone que las decisiones de la empresa contemplaban el control, manejo, manipulación y dominio de los recursos de manera más o menos excluyente de otros grupos. Esto pudo ser posible gracias a la existencia de un mercado agrario en torno a la industria, a la capacidad de consumo de azúcar en áreas no rurales y a un sistema de cambio estable, como se ve en el libro de cuentas. La economía azucarera se estructuró en función de las necesidades del consumo interno, lo que la distingue de otros sectores productores coloniales ${ }^{12}$. Efectivamente, el ingenio San Nicolás Tolentino proveía de azúcar a la villa de Atlixco, Puebla y ciudad de México. En Puebla, por ejemplo, el mercado consumidor rebasaba a la propia ciudad, encontrándose compradores "forasteros" sin identificar su procedencia, y otros de Tlaxcala, Cholula, Huetzotzingo, Chiapas, Guadalajara y de “tierra adentro”, así como también los conventos de Santa Catalina, Santa Inés, Santa Teresa y San Antonio ${ }^{13}$.

Esta apreciación encuentra relación con los niveles de producción de San Nicolás Tolentino dentro de la producción total de azúcar en Nueva España, calculada por Horacio Crespo, para 1694-1697, en 14.776 arrobas en promedio. En 1694, el ingenio produjo 16.724 arrobas (192 toneladas), más de dos veces la producción del ingenio Santísima Trinidad un siglo antes, cuando el promedio para la producción entre 1650-1700 se ha calculado en 8.530 arrobas anuales y, para la segunda mitad del XVII, en cien toneladas en promedio ${ }^{14}$. Cabe preguntarse cuál fue el factor esencial que la empresa debía controlar y usar racionalmente para obtener estos niveles de producción. Si anotamos las relaciones regionales que mantiene el ingenio dentro del funcionamiento normal y necesario, tenemos un primer grupo constituido por los mercados-lugares de consumo ya anotados y un segundo más numeroso, constituido por los pueblos de indios de Cuilocán, Huetzotzingo, Tochimilco, Santa María Nativitas, Tepeojuma, Guyluco, Cholula, Teopantlán, Matzaco, Santa Ana, Ayotlam o Ayutla, Atzala, Atlixco e Izúcar ${ }^{15}$. Con ellos se establecen relaciones comerciales de aprovisionamiento de carbón y vestuario, pero principalmente de adquisición de mano

12 Crespo, Historia del azúcar, 2: 14.

13 “Venta de los azúcares de la Villa de Atlixco este año de 1694”, AGN, Concurso de Calvo, vol. I, exp. 15; “Cuaderno de venta de las azúcares de la Puebla”; AGN, Concurso de Calvo, vol. I, exp. 16; “Venta de azúcar por Dn. Joseph Calvo vecino encomendero de la ciudad de México”, AGN, Concurso de Calvo, vol. I, exp.17.

14 Crespo, Historia del azúcar, 1: 139-140.

15 Véanse, en el Anexo 1, las Tablas 1 y 2. 
de obra en cuadrillas de trabajadores, grupos de indios o trabajadores contratados individualmente. Los pueblos de Santa Ana, Cuilocán, Ayotla Atzala, Cholula e Izúcar proveían al ingenio del 99,4\% del total de la mano de obra requerida (para todas sus áreas) en un año.

La obtención de mano de obra fue el frente adverso más importante que debió controlar el ingenio de San Nicolás Tolentino y lo que lo llevó a una primera racionalización de la producción. Esa decisión involucró en primer lugar la fuerza de trabajo, pero también un mejoramiento mecánico, al fabricar una prensa para el procesamiento de la caña, aunque no se puede afirmar si las medidas adoptadas para controlar la producción, de manera favorable, fuesen causa del alto nivel de rendimiento del ingenio en la época respecto de sus pares. Los datos regulares, organizados por materias, comienzan en 1693, siendo 1694 el año de anotación más rigurosa y completa. La mano de obra fue un frente adverso, por ser el recurso más disputado durante todo el siglo XVII, pues a mediados de él, la población autóctona llegó a su nivel más bajo demográficamente. Esta era requerida por la agricultura de todo tipo y más aún por la cañera, por cuanto se cultivaba y procesaba todo el año. Sin embargo, no era la mano de obra residente todo el año en la hacienda e ingenio la que cubría las necesidades. Pero, ¿̇a qué obedecía esa decisión? ¿Esta observación tendrá relación con el principio de que la actividad económica no capitalista racionaliza la producción merced a contingencias extraeconómicas y por tanto la lógica de la actividad no obedece completamente a las exigencias del mercado? Agreguemos que la segunda mitad del siglo XVII ha sido definida como el inicio de la depresión en los precios del azúcar y eso significa que el ingenio de San Nicolás Tolentino tuvo una producción por encima del promedio en años de escasez de población y en condiciones de comercialización desfavorables. Entonces, ¿las estrategias de uso de mano de obra respondieron al fin de disminuir los costos de producción o al de hacer un uso extensivo del recurso para aumentar la producción y vender más por menos precio, pero manteniendo los niveles de ingresos necesarios para continuar la empresa? Como la muestra de datos corresponde solo a un año, habría que conocer el comportamiento posterior de la empresa, para establecer si la estrategia se mantuvo o no.

El ingenio de San Nicolás Tolentino organizaba el fin de la actividad económica de acuerdo con presiones extraeconómicas, en este caso, la disponibilidad de mano de obra, para poder producir ventajosamente en un mercado desfavorable a través del uso extensivo de la misma controlando también su sobreoferta cuando aumentó su número total o local. Por ejemplo, cuando se expresa que se dio trabajo a los indios de Cholula "porque lo pidieron”, pagándoles menos salario del que correspondía, incluidas las mujeres ${ }^{16}$. Claro que para un análisis más certero también habría que considerar que no necesariamente la oferta de mano de obra aumenta por un incremento en

16 La información y los análisis se basan en las Tablas 1 y 2 del Anexo 1. 
su número real, ya que puede deberse a la disminución o inexistencia de restricciones a su uso. También se puede considerar lo que anota Carlos Paredes respecto a que, a mediados del siglo XVI, en el valle de Izúcar hubo especializaciones regionales de producción por exigencia de mercados externos o locales, por lo que muchas comunidades ya no eran autosuficientes y tuvieron que buscar en el trabajo "asalariado" un complemento a sus necesidades de subsistencia o de pago de tributo.

Apoyaría esta reflexión lo expresado por Gisela von Wobeser respecto al funcionamiento de los ingenios en Morelos durante el período colonial. Las múltiples tareas y producciones asociadas a su funcionamiento requerían que la fuerza de trabajo fuese de una magnitud y complejidad tales que la convertían en uno de los factores cruciales de la industria, absorbiendo la mayor parte de los gastos de operación ${ }^{17}$. Aceptando que la producción en esta etapa de la gran propiedad entendida como empresa estaba determinada por el factor extraeconómico de la población disponible como mano de obra, su manejo eficiente se regía por una política demográfica que tenía por objeto obtener mano de obra para cada especialización dentro de las labores del ingenio. Esta política de “población” tenía que ver con el tipo de trabajo que se ocupaba: esclavo o libre, permanente o estacional, especializado o no, pero también con las estrategias de retención de mano de obra por crédito o deudas, protección, fomento de matrimonio, ayuda en fiestas religiosas, entre otras.

\title{
El predominio de las cuadrillas sobre los sirvientes de razón: una política de población
}

\author{
[...] pagué al capitán de Santa Ana dies y seis \\ pesos cuatro reales que le debía de sesenta y seis \\ indios digo tareas que ha cortado de más [...] \\ [...] al capitán de Cuilocán veinte pesos paraque \\ saque ochenta indios desde hoy [...] \\ [...] en dicho día cinco pesos y seis reales que \\ se les pagaron a los indios de Cholula de la segunda \\ cuadrilla del día de ayer que trabajaron \\ que pidieron se les diese $[. . .]^{18}$
}

El ingenio azucarero requería mano de obra permanente durante todo el año porque todo el tiempo se cortaba y elaboraba la caña: desmonte, barbecho, surcada, apantleo, siembra, resiembra, riegos, escardas, corte. Solamente en el último cuarto del siglo XVIII el ciclo azucarero se dividió en dos: zafra y tiempo muerto ${ }^{19}$. En 1694, el inge-

17 Gisela von Wobeser, La hacienda azucarera en la época colonial (México: SEP; UNAM, 1988), 300.

18 "Cuenta y razón de los salarios que han ganado en este ingenio de San Nicolás de Tolentino los sirvientes que en él se han acomodado y servido desde primero de enero de 1694 hasta fin del, conforme sus cuentas ajustadas que se hallaran en el libro intitulado sirvientes año de 1694”, AGN, Concurso de Calvo, vol. I, exp. 8, fols. 199-200.

19 Véase Crespo, Historia del azúcar, vol. 1; Scharrer, Azúcar y trabajo. 
nio de San Nicolás Tolentino contaba con 113 esclavos (0,3\% de la fuerza de trabajo) entre hombres, mujeres y muchachos, necesitando entre 40 y 45 sirvientes permanentes $(0,1 \%)$ en el año y la fuerza de 29.964 indios de cuadrillas $(99,4 \%)$ para cubrir todas las etapas de la producción del azúcar. Los indios de cuadrillas cubrían todas las labores relacionadas con el cultivo de la caña, representando el $48,1 \%$ del gasto total en insumos del ingenio en un año. Siguiendo un uso tradicional en la historia del trabajo azucarero, los esclavos negros ocupaban los puestos relacionados con vigilancia de labores (mandones, mayordomos) y las tareas especializadas relacionadas con la refinación del azúcar. Pero junto a ellos encontramos "sirvientes" contratados por semanas, meses o años que residían en la hacienda ejecutando tareas del campo, en la caña o en los cultivos necesarios para las raciones, y se dedicaban a la crianza de ganado dentro del ingenio. ¿A qué se debía el uso mayoritario de población indígena libre no residente en las haciendas?

Carlos Paredes distingue dos etapas en el tema del trabajo en cañaverales e ingenios en el valle de Izúcar. La primera abarcaría todo el siglo XVI. Durante la misma incluso los propios indios tenían cultivos de caña, como en Tepeojuma, en 1590, y los ocupaban por vía de repartimiento para construir casas o ingenios, aunque para la región de estudio no se tienen datos sobre el uso de este mecanismo. Una disposición virreinal de 1601 prohibió utilizar el repartimiento para trabajos dentro del ingenio o trapiche, mas lo permitía para las faenas en los cañaverales. Paralelamente, desde 1590, se menciona en los textos una reserva de los indios de Izúcar y Chietla para trabajar en las haciendas del valle de Atlixco. También se recurría a la esclavitud negra y a mestizos e indios en alquiler voluntario. La segunda etapa se inició en 1600 desde la prohibición del uso del repartimiento, a partir de lo cual se supone que aumentó el alquiler voluntario de fuerza de trabajo ${ }^{20}$. Según esto, lo señalado para el ingenio San Nicolás Tolentino estaría dentro de una práctica de reclutamiento de mano de obra tradicional en la región, condicionada por el alcance de las disposiciones legales.

El alquiler en el siglo XVI no suponía una dependencia total de los trabajadores indios al salario, porque aún estaban ligados a sus comunidades, ¿̇pero sucedía lo mismo en el XVII? Entre los trabajadores de San Nicolás Tolentino se distinguen claramente dos tipos de asalariados consignados en el libro de cuentas: los indios de cuadrilla y los anotados como "sirvientes". Los primeros siempre son designados como indios pero a los segundos no se les atribuye ninguna calidad étnica, solo sus funciones. La diferencia entre sirvientes e indios de cuadrillas también venía de las modalidades del salario en especies y del tiempo de permanencia en la hacienda. Los primeros recibían raciones de alimento y vestuario anuales y residían en la hacienda con sus familias. Algunos de ellos eran llamados también gañanes y otros eran esclavos (los de oficios

20 Paredes, El impacto de la conquista, 82. 
específicos o cargos de administración). Su salario en metálico era mensual, ajustable a fin de año. En cambio, el indio de cuadrilla recibía un salario variable de acuerdo con el cumplimiento de las tareas asignadas, ya fuesen de corte, de riego o de siembra de la caña; además habitaba en su pueblo y no recibía vestuario por parte del administrador de la hacienda. En el cuaderno de sirvientes también se enlistan los contratados por semanas o para tareas específicas de desgrane de legumbres, ensacado de maíz y otras.

El uso de distintas calidades de trabajadores era un asunto de costos que consideraba el nivel de calificación requerida y el mayor o menor trabajo según las diferentes etapas de la cadena productiva del azúcar. Así, pagar dos reales a cada trabajador para las tareas permanentes relacionadas con el cultivo de la caña -que requería muchos brazos en forma intensiva, sin gastos en raciones o vestuario y con el incentivo de aumentar el salario si se realizaban más tareas de las acordadas- reducía el costo de producción de la materia prima. Sin embargo, aunque no se hizo el cálculo de sumar al salario expresado en moneda lo que sería el valor de las especies entregadas por ración, por cuanto no hay un índice de precios para cada una de ellas, sí puede observarse que el salario más común de tres pesos cuatro reales, descontando los días domingos, hace un promedio de 1,2 reales diarios. Si las especies repartidas en las raciones se producían en un 90\% dentro de la hacienda, era porque el propio trabajador pagaba su costo de producción. La ventaja no solo venía del menor costo de un trabajador a libre disposición del empleador, sino de que también se lo requería para todas aquellas labores que siempre tenían imprevistos, como el mantenimiento del trapiche, la prensa, las calderas, y todas esas pequeñas tareas cotidianas de mandar recados, acarrear leña, reemplazar a los enfermos, trabajadores que quedaron consignados con la expresión "para lo que se les mandase". La mano de obra esclava se destinaba, como señala la historiografía del azúcar, a esas labores que requerían un conocimiento dado por la experiencia, por lo que convenía entregarlas a personas que legalmente no podían irse de la hacienda, quedándose con ellos el conocimiento adquirido a lo largo del tiempo. Los esclavos también ocupaban los cargos de más confianza, aquellos que requerían lealtad y complicidad con el poder patronal, como los de mayordomos o supervisores de tareas ${ }^{21}$.

La lógica era usar un tipo de trabajador para cada función, aunque predominaban los especializados sobre los de todo servicio, pues se reducía el margen de error en cada

21 Véanse Crespo, Historia del azúcar; Scharrer, Azúcar y trabajo; “Trabajadores y cambios tecnológicos en los ingenios (siglos XVII-XVIII), en Trabajo y sociedad en la historia de México, siglos XVI-XVIII, Gloria Artís Espriu y otros (México: Ciesas; SEP, 1992), 149-186; Wobeser, La hacienda azucarera; Ward Barret, La hacienda azucarera de los marqueses del valle (1535-1910) (México: Siglo XXI, 1977); Jan Bazant, “El trabajo y los trabajadores en la hacienda de Atlocomulco”, en El trabajo y los trabajadores en la historia de México, comp. Elsa Frost (México: El Colegio de México; University of Arizona Press, 1979), 378-390; Ward Barret y Stuart B. Schwartz, “Comparación entre dos economías azucareras coloniales: Morelos, México y Bahía, Brasil”, en Haciendas, latifundios y plantaciones en América Latina, coord. Enrique Florescano (México: Siglo XXI, 1975), 532-572. 
una de las etapas, y quizás eso sea lo que se refleja en la asociación de una especialidad con el pueblo del que provenía la cuadrilla. Los indios de Santa Ana y Cuilocán cortaban caña, los de Ayutla e Izúcar la sembraban. Los regadores tenían una relación clara con un pueblo o comunidad y era responsabilidad del mayordomo del ingenio su contratación. Posiblemente los capitanes de regadores los reclutaban por su cuenta y ofrecían su cuadrilla personalmente. El libro de cuentas no da ningún dato respecto a su calidad étnica, su lugar de residencia o su procedencia. El uso de los regadores nos habla de un control sobre el uso del agua, ya que se calculaba día a día la cantidad que se necesitaba de ellos según los requerimientos de la planta de azúcar. La mano de obra indígena era aprovechada masivamente en el ingenio San Nicolás, equilibrándola mediante el uso de gente de distintos pueblos según el año, quizás en un acuerdo de costumbre que recordaba los tiempos del repartimiento. De esta manera también se controlaba el desgaste de la misma. Cada pueblo empleaba una mayor cuota de indios en meses intercalados.

De alguna manera, se puede ver en estos detalles la existencia de un mercado de mano de obra competitivo y ventajoso, si venían desde Cholula a trabajar y había sujetos traídos desde allí o Atzala para ofrecerlos en el día. La creación de este mercado se vio favorecida cuando, a comienzos del siglo XVII, período de depresión de la industria azucarera en Nueva España, se aplicó una política estatal para no proveer mano de obra agrícola, dejando el problema a negociaciones "privadas". Durante el siglo XVII, tanto los virreyes Cerralvo como los Cadereyta dictaron varias disposiciones para frenar los abusos derivados de este laissez faire. Por ejemplo, el 13 de junio de 1630 se encarceló al dueño de un trapiche en Miacatlán, Cuernavaca, por obligar a los indios del pueblo a trabajar para él, azotándolos y cortándoles el agua. En 1639, el virrey Cadereyta amonestó a Marcos Pérez, dueño del ingenio San Nicolás Tolentino en ese entonces, por enviar a sus mayordomos y criados a barrios de indios para conseguir forzadamente mano de obra y por dar dinero a las mujeres para comprometer a los maridos. Joseph de Avilés pudo ser uno de los continuadores de este sistema al traer a algunos indios de Atlixco a las labores de la hacienda de forma esporádica, pero quizás su función ya no era tan esencial en 1694, al establecerse acuerdos directos entre los capitanes de los pueblos o sus respectivos gobernadores y el ingenio, como el que se hizo con Cuilocán, por el cual recibió un pan de azúcar de 14 libras dado por el propio “señor Fernando” dueño del ingenio ${ }^{22}$.

\section{La política de población y el control de los patrones de uso de mano de obra}

En el ingenio San Nicolás Tolentino las cuadrillas de indios constituían el 99,4\% de la fuerza de trabajo y los sirvientes, el 0,1\%. Esto significa que gran parte de las decisiones del ingenio al respecto buscaban mantener el flujo constante de trabajadores li-

22 “Azucares vendidas, dadas y racionadas este año de 1694”, AGN, Concurso de Calvo, vol. I, fol. 414. 
bres, los que, teóricamente, tenían libertad para contratarse con quien quisieran y en lo que quisieran, puesto que el repartimiento estaba abolido desde 1632. He señalado que para el caso de los trabajadores de cuadrillas, cuyos capitanes estaban asociados a algún pueblo de indios, debió existir una política de negociaciones con los principales y gobernadores de los mismos que asegurara una cantidad permanente de indios. El libro de cuentas muestra que las había y, junto con ellas, el uso del pago por adelantado de cierto número de tareas o indios, acción que los comprometía en su cumplimiento. Y se cumplía con creces, porque era habitual ajustar cuentas de tareas extras. No puede obviarse la presión a la que se veían sometidas las comunidades al aceptar esta modalidad, dado que ya no eran autosuficientes y requerían de metálico para abastecerse de lo necesario para subsistir. Con esto se sellaba el círculo del mercado, porque al destinar gran parte de sus hombres y mujeres al trabajo asalariado difícil era restablecer la autoproducción, ya fuese de alimento o de vestuario.

Lamentablemente, el libro de cuentas no proporciona más información que ayude a determinar los mecanismos de obtención de este tipo de trabajadores. Sin embargo, es pertinente discutir un poco con la historiografía el tema de los trabajadores libres "asalariados". Si se quisiera identificar al indio de cuadrilla dentro de alguno de los sistemas señalados en los textos, tales como los de los "tlaquehuales", "naboríos", "gañanes” o "peones acasillados”, optaría por la primera categoría y, asumiendo la definición de Gisela von Wobeser, diría que estos son los trabajadores empleados por días, pagados diariamente o por semanas ${ }^{23}$. Ya se ha dicho que, según los datos del libro de cuentas, no recibían raciones ni vestuario, ni residían en la hacienda. La categoría de sirvientes correspondería al sistema de la gañanía, aquellos trabajadores que se concertaban por un salario mensual ajustado a fin de año, recibiendo ración alimenticia y residiendo en la hacienda junto a sus familias por períodos superiores al año. La cuestión es cómo el gañán llegaba a serlo. En la bibliografía sobre el tema siempre se señala al repartimiento como institución que permitió la formación de un incipiente mercado de mano de obra libre o, por lo menos, fuera del sistema de encomienda. Así, tanto gañanes como tlaquehuales tendrían el mismo origen, aunque también se anota que, independientemente de la encomienda o el repartimiento, el alquiler voluntario individual se practicaba, aunque no masivamente. Entre 1628 y 1632, el gobierno virreinal emitió, junto a las disposiciones que prohibían el repartimiento, otras que dejaban a los hacendados pagar los tributos de los indios, dándoles acceso a la mano de obra indígena por medio de las deudas ${ }^{24}$.

Otro autor, Ward Barret, no utiliza la nomenclatura anterior y habla de trabajadores "ordinarios" y "extraordinarios". Los primeros trabajaban fuera de sus pueblos como complemento de la obligación de las comunidades de enviar determinado porcentaje

23 Wobeser, La hacienda azucarera, 293.

24 Ibídem, 286. 
de sus hombres a trabajar por semana para los españoles, y los extraordinarios se reclutaban para satisfacer las necesidades cuando no alcanzaban los demás. Los ordinarios serían los indios de cuadrillas de nuestro caso y los extraordinarios, los sirvientes contratados por períodos cortos. Según Barret, los trabajadores ordinarios eran "indios de semana”, de lunes a sábado por la tarde, y los identifica con los indios de repartimiento abolidos en la primera mitad del siglo XVII ${ }^{25}$. A los extraordinarios se les pagaba por intermedio de los principales (como a nuestras cuadrillas) y a los ordinarios, individualmente (como a los sirvientes), por lo que la identificación de nuestro caso con esta nomenclatura no es total. Estas categorías de trabajadores estarían dadas por las necesidades de los ingenios, pero junto a ellas también encontraríamos indios naboríos que eran especializados, recibían salario y residían en la plantación. Habría dos categorías de naboríos: los dependientes y los peones. A estos últimos el autor dice que no los puede explicar aunque posiblemente eran "asistentes del labrador español" hay consenso en el uso de los términos y tampoco claridad en las explicaciones.

Por otra parte, Isabel González Sánchez, hablando para el siglo XVIII y la zona de Tlaxcala, relaciona al gañán con el repartimiento, por cuanto es un trabajador que alquila su fuerza de trabajo, pero que va quedando anclado a la hacienda por deudas. El tlaquehual sería un indio de apoyo al trabajo del gañán. Se alquilaba voluntariamente para laborar por un tiempo determinado (plazo máximo de un año), ganando siete u ocho pesos al mes, cuando el gañán ganaba tres pesos con cuatro reales. La autora menciona que hacia 1772 numerosos documentos hablan de la presencia de "gañanes tlaquehuales"27. Herbert Nickel, estudiando las haciendas de Puebla-Tlaxcala en el XVIII, es más específico; dice que los tlaquehuales eran los indios contratados en los pueblos, mientras que los gañanes eran trabajadores asalariados concertados voluntariamente; es decir, habría una diferencia centrada en el punto de origen de quien se desplaza para contratar: el propio trabajador va hacia el centro de trabajo o el centro de trabajo va por los trabajadores. Este autor también introduce el concepto de peón para aquellos trabajadores estables de las haciendas, ya sea por deudas (acasillados o calpaneros) o porque el tributo lo pagan en la hacienda (adscripticios). Sin embargo, el autor habla de reclutamiento y peonaje como dos situaciones que afectan a los "gañanes indígenas", por tanto, el gañán es el trabajador libre asalariado, sea tlaquehual o pura y llanamente gañán ${ }^{28}$.

25 Barret, La hacienda azucarera, 198-199.

26 Ibídem, 206.

27 Isabel González Sánchez, "La retención por deudas y los traslados de trabajadores tlaquehuales o alquilados en las haciendas como sustitución de los repartimientos de indios durante el siglo XVIII", Anales del INAH (México), tomo XIX, núm. 48 (1967): 241-250. También, Charles Verlinden, "El régimen de trabajo en México: aumento y alcance de la gañanía. Siglo XVII”, en Historia y sociedad en el mundo de habla española. Homenaje a José Miranda, eds. Bernardo García y otros (México: El Colegio de México, 1970), 225-246.

28 Véase Herbert Nickel, "Reclutamiento y peonaje de los gañanes indígenas de la época colonial en el altiplano Puebla-Tlaxcala”, en Relaciones de trabajo en las haciendas de Puebla y Tlaxcala (17401914). Cuatro análisis sobre reclutamiento, peonaje y remuneración (México: Universidad Iberoamericana, 1987), 23-62. 
Ya en la segunda mitad del siglo XVIII, un documento de la ciudad de Tlaxcala, que denuncia el mal trato y las condiciones de semiesclavitud en que vivían los trabajadores indios de las haciendas, señala que los hacendados se servían de dos clases de indios: los tlaquehuales y los gañanes. De los primeros dice:

[...] se alquilan por cierto tiempo, que no excede de un año, a su voluntad y esto, a la parte que más le adapta, con la persona que quiere y por el justo jornal que es costumbre y se conviene con el labrador, sin que intervenga fuerza ni violencia, señalándoles por cada día real y medio y su correspondiente ración, que vale medio real, con lo que verifica gana el indio tlaquehuales en la parte que menos, dos reales diarios sin que por esto sea obligado la mujer e hijos a servir al labrador. Y cumplido el tiempo con que ha salido concertado, liquidada su cuenta, vuelve al pueblo de su vecindad, para libremente usar de su persona, quedándose en él o por nuevo convenio ir a la misma parte o a otro que más le convenga ${ }^{29}$.

De los segundos:

[...] son indios en que los labradores quieren tener derecho, sujetándolos a servidumbre porque les juzgan adscritos a las fincas. A estos pagan, en la parte que más veinte y ocho reales (3p5r) por treinta días, con más una fanega de maíz, de que es suprema valor ocho reales. De manera que el todo de la ganancia del gañán en treinta días de trabajo son treinta y seis reales (4p5r), por lo que le es preciso, o vivir con su mujer en la hacienda en perpetua servidumbre, sin que puedan salir $[\ldots]^{30}$.

El documento también se refiere a que también la mujer e hijos del gañán eran aplicados al trabajo en la hacienda, dándoseles solo vestuario. Esto es, que ambos van resultando ventajosos para la empresa en términos de costos, ya sea porque unos pueden ser contratados según las necesidades inmediatas y otros están por si se los necesita. Pero, tal como se ha dicho, hay que ver en cada empresa en particular cuál tipo de trabajadores es el más conveniente o en qué momentos. Si nos guiamos por el documento citado, para definir el tipo de trabajador por el salario, tenemos que en el ingenio San Nicolás Tolentino el término sirvientes englobaba tanto a gañanes y gañanes tlaquehuales como a esclavos. Por consiguiente, sirviente sería todo trabajador que no se iba a su pueblo diariamente. En términos de salario, los que ganaban más de 10 pesos mensuales eran trabajadores esenciales tanto para la administración como por tener alguna especialidad: los mayordomos, el purgador, el maestro carpintero y los arrieros. Podríamos decir que los mandos medios o sujetos aplicados a tareas no

29 Carlos Sempat Assadourian y Andrea Martínez Baracs, "Representación de la ciudad de Tlaxcala sobre la condición de los gañanes, 1767”, en Tlaxcala, textos de su historia. Siglos XVII-XVIII, vol. 7 (México: Conaculta-Gobierno de Tlaxcala, 1991), 225-237.

30 Ibídem. 
tan sofisticadas, pero con algún grado de responsabilidad, ganaban entre cuatro y cinco pesos; estos eran los mayordomos del ganado, voyeros, el guardacañas, los vaqueros, el guardamilpas, el panadero y el guardacaballos. Los gañanes “de hacer lo que se les mandase” ganaban tres pesos con cuatro reales. Para labores de confianza se ocupaban gañanes tlaquehuales y para las de menos especialización, gañanes.

Sin embargo, la muestra del salario de un año no da cuenta de la calidad del trabajador, porque se observa en el libro de cuentas un cierto grado de movilidad de la mano de obra, ya sea por despidos o por ascensos, que coinciden con cambios salariales. Por ejemplo, Francisco de Herrera, señalado como “el portugués”, del 1 de enero al 1 de junio de 1694 se "asentó” por seis pesos para “trabajos de hacienda” y desde ese día pasó a ser el mayordomo de la estancia de Nopala con un salario mensual de 10 pesos más ración de 38 pesos de cacao, dos pesos de canela, un pan de azúcar, una fanega de maíz y media arroba de miel cada quince días, 20 candelas al mes y ración de vaca y carnero cada quince días ${ }^{31}$. Se puede objetar que el trabajador no era indio, pero lo interesante es eso, la posibilidad de que los gañanes fuesen españoles, mestizos o de otro origen. Los gañanes tlaquehuales "para lo que se les mandase" recibían ración (otra distinción con el tlaquehual de cuadrilla) que consistía en una fanega de maíz, miel y carne. Las raciones también marcan distinciones y tienen relación con el salario. Por ejemplo, Tomás de Castañaza trabajó cinco meses para lo que se le mandase, pero por un salario de ocho pesos mensuales, la ración acostumbrada y chocolate; en el libro de cuentas no se especifica ${ }^{32}$. Ahora, en el salario también influye la calidad jurídica (libre o esclavo) del trabajador, que no se especifica en el libro de sirvientes. Por ejemplo, Thomás Hernández aparece como voyero gañán, pero también está en la lista de esclavos de la hacienda, asentándose desde marzo con un salario de dos pesos mensuales y "ración de soltero" 33 . Pero hay casos en los que se puede decir con seguridad que se trataba de un gañán tlaquehual, como el de Andrés de Aragón, que se "acomodó por catorce días para lo que se le mandase” con un salario de cuatro pesos, se marchó debiendo un peso y seis reales, pero regresó dos meses después para acomodarse otra vez con igual salario ${ }^{34}$. Para poder saber con seguridad si el trabajador era un tlaquehual o un gañán sería conveniente confeccionar una especie de historial del mismo que abarcase el total de años de servicio en el ingenio y los movimientos que efectuaba en ese año.

No obstante, se puede aventurar una clasificación para el ingenio San Nicolás Tolentino a fines del siglo XVII, tomando en cuenta las definiciones de la bibliografía y la del

\footnotetext{
31 "Cuenta y razón de los salarios que han ganado en este ingenio de San Nicolás de Tolentino los sirvientes que en se han acomodado y servido desde primero de enero de 1694 hasta fin del, conforme sus cuentas ajustadas que se hallaran en el libro intitulado sirvientes año de 1694", AGN, Concurso de Calvo, vol. I, exp.8, fol. 242v.

32 Ibídem, fol. 243v.

33 Ibídem, fol. 243v.

34 Ibídem, fol. 244.
} 
documento señalado para un siglo después en Tlaxcala. Existían dos tipos de indios tlaquehuales. El de las cuadrillas, que funcionaba dentro de un sistema asociado a la estructura de los pueblos de indios, por lo que el acuerdo de su remuneración lo tranzaba un tercero -gobernador o capitán-, y no residía en las haciendas, trabajando por días. El segundo sería un tlaquehual gañán cuyo contrato era individual, sin mediación de terceros y por períodos máximos de un año. Un tercer grupo de trabajadores sería el de los gañanes, residentes en la hacienda por tiempo indefinido. Sin embargo, un tlaquehual podía devenir en gañán. Los datos con que se cuenta permiten detectar los mecanismos por los cuales los trabajadores residentes podían ir perpetuando su estancia y con ello ir transformándose en gañanes, y saber cuáles eran las razones por las que, aunque fuese conveniente en costos mantenerlo, se lo echaba de la hacienda. Esto es, la política demográfica o de "población” de la empresa de azúcar de San Nicolás Tolentino.

Según la historiografía sobre tlaquehuales, gañanes y peonaje que se ha consultado, uno de los temas centrales en las estrategias de captura de mano de obra por parte de las empresas coloniales fue la retención por deuda. Entre 1632 y 1635, se fue facultando a los hacendados para que pagaran el importe de los tributos de los gañanes que tenían matriculados en sus haciendas y también para que pudieran descontar de sus salarios las sumas que les anticipaban, legalizando la retención de ellos por deuda “legal”. Zavala explica de dónde venía la deuda del tributo:

[...] en la gañanía, el indio no tributaba en provecho del dueño de la hacienda, sino que esta pagaba al fisco real por el indio matriculado en su hacienda y a su vez lo recobraba en trabajo personal del sirviente ${ }^{35}$.

En el caso en estudio, de fines del siglo XVII, no se puede afirmar que todos lo gañanes y tlaquehuales fuesen indios, excepto los tlaquehuales de cuadrillas. Por tanto, el origen de la deuda de los gañanes no se puede establecer con tanta claridad, aunque no se descarta esa vía. Los gañanes tlaquehuales y gañanes del ingenio en un $90 \%$ recibieron entre $20 \%$ y $50 \%$ de su salario adelantado durante el año. Esto quiere decir que la deuda aseguraba el cumplimiento del servicio o por lo menos establecía un compromiso de hacerlo. El uso frecuente del sistema señala cierta efectividad en los resultados, porque no es creíble que se tolerase fugas de capital en el contexto de una mano de obra disputada por otros empresarios y precios desfavorables para el producto. La práctica del despido también indica que no se retenía a cualquier trabajador; de hecho, los más endeudados eran los especializados y administradores. Acepto la tesis de Herbert Nickel en cuanto a que la deuda era una inversión para asegurar mano de obra, capitales en forma de crédito o préstamo, que en caso de inseguridad en su retorno se cortaban ${ }^{36}$.

35 Véase Silvio Zavala, “Introducción”, en Fuentes para la historia del trabajo en Nueva España, vol. 0 (México: Fondo de Cultura Económica, 1939), vii-ix. También, Isabel González Sánchez, Los trabajadores alquilados de Tlaxcala para las haciendas foráneas. Siglo XVIII, Cuadernos de Trabajo del Departamento de Investigaciones Históricas, No. 13 (México: INAH, 1976).

36 Véase Nickel, "Peonaje e inmovilidad de los trabajadores agrícolas en México. La situación de los calpaneros en las haciendas de Puebla-Tlaxcala”, en Relaciones de trabajo, 87-155. 
La deuda tenía diversos usos. Primero, como inversión para asegurar mano de obra no solo en forma de enganche sino también para impedir el retiro del trabajador terminado su contrato. En el libro de sirvientes se anota: “a Gaspar López a su cuenta 2 pesos cuando se quería despedir"37. También para obligarlo al enganche al pagar al antiguo patrón lo adeudado. En San Nicolás Tolentino se tenía una deuda con Antonio de Obrego, la cual se pactó en plazos por un número de "sirvientes”, que no se especifica:

Domingo 4 de julio: 24 pesos 2 reales de mi descargo que libre a doña María Pérez en el capitán Thomás de Yevenes, de cuenta de las deudas de los sirvientes a su esposo Antonio de Obrego y pertenece este plazo del mes de junio ${ }^{38}$.

En segundo lugar, la deuda obligaba al trabajador a monetarizar su propia economía por cuanto son muchos los ejemplos de peticiones de adelantos o préstamos en especies, vacas, alimentos o vestuario, y de que se le daba el equivalente en moneda y más de lo pedido. Esto lo obligaba a calcular en términos de trabajo adeudado más que en raciones o préstamos:

A Juan Calaorra guarda milpa le di 1 peso cuando pedía 6 reales para medias. [...] a Sebastián de la Cruz guarda caña que pedía 2 reales le di 6 reales.

[...] en dicho día Melchor Frías 12 reales que lo llevó su mujer cuando pedía maíz. [...] en dicho día a Juan Muñoz 2 pesos a su cuenta cuando pedía una vaca. A Juan de Vargas boyero 2 pesos que dijo que estaba perdido que no tenía qué comer ... ${ }^{39}$.

En tercer lugar, la deuda se utilizaba como mecanismo de captura de familias biológicas financiando matrimonios, partos, bautizos, enfermedades y defunciones. Juan Nopala, por ejemplo, recibió adelantado el salario de un mes para poder casarse ${ }^{40}$. Esta política “familiar” permite ver cuán anclado o no a la hacienda estaba el trabajador. Por ejemplo, Onofre Grabriel, un vaquero gañán, pidió licencia para ir a ver a sus parientes y se le dieron dos pesos para que pudiera hacerlo, o Miguel Hernández, a quien se le dio un peso para su hijo enfermo, o la mención de Juan de Hinojosa el Viejo (para diferenciarlo de su hijo Juan de Hinojosa el Mozo), que debía cuatro pesos y cuatro reales, pero no aparece en la lista de sirvientes. Quizás ya no estaba en servicio pero seguía residiendo en la hacienda, porque era parte de la familia de su hijo, quien ahora desempeñaba la misma función que él. De ellos sí podemos decir que eran peones acasillados ${ }^{41}$. O también el financiamiento del traslado de la familia a la hacienda, como a Antonio de Solís, que recibió cinco pesos para ir a buscar a su mujer.

\footnotetext{
37 "Memoria del gasto ordinario desde $1^{\circ}$ de enero desde 1694 hasta diciembre", AGN, Concurso de Calvo, vol. I, exp. 5, fol. 156.

38 Ibídem, fol. 178.

39 Ibídem, fols. 168v., 149, 194, 199, 206, respectivamente.

40 Ibídem, fol. 194v.

41 Ibídem, fol. 166v.
} 
Si bien las mujeres no estaban obligadas a servir, jugaban un papel esencial en la petición de dinero a la cuenta de sus esposos, tanto para financiamiento de asuntos personales como para satisfacer necesidades de la familia:

Agona esposa de [ं?] lleva 1peso a cuenta de su marido porque murió el padre de ella.

A la mujer de Nicolás de Viña 1peso, cuando fue a la novena de Tecpansingo. Nicolás de Viña, su mujer compró un peso de azúcar con cuatro que le prestaron $^{42}$.

También el marido recibía dinero para comprometerlo con el trabajo de la esposa: "Diego Méndez recibe cuatro pesos para que su mujer vaya a la purga" ${ }^{43}$. La política de población dentro de la hacienda era el factor esencial de la racionalización: el uso de toda la fuerza disponible para hacerla producir. Incluso a aquellas unidades que no era necesario que lo hicieran se busca la manera de sacarles utilidad, como, por ejemplo, la decisión del dueño del ingenio de terminar con una tradición (darle naguas a las mujeres libres, esposas de esclavos) introduciendo una lógica de costo-beneficio inusitada, tanto, que queda escrita como una “declaración”:

Es declaración que este año se le dieron a todas las esclavas del ingenio las naguas de bayeta que se habían llevado para las mujeres libres casadas con esclavos como era costumbre asentada desde tiempo del licenciado don Felix el dárselas y reconociendo el capitán Martín Calvo que las dichas mujeres de esclavos no servían de útil al ingenio y que aunque se le mandare alguna cosa no la hacían, no se pudo conseguir él a más de ellas el hacer ordeño, se diese a dichas esclavas en premio de las faenas que hacen $[\ldots]^{44}$.

\section{La deuda, especies “dadas” y repartimiento entre los trabajadores: patrones de consumo y gasto}

Si bien la deuda era instrumental para la necesidad de la empresa de retener un número de trabajadores necesarios todo el año dentro de ella, también refleja la dimensión subjetiva o la dimensión cultural de la satisfacción de las necesidades. Un 20\% para alimentos, 10\% para cubrir deudas personales con otros trabajadores, $15 \%$ para vestuario, $5 \%$ para financiamiento de "estatus" (ingresar a cofradías, compadrazgo, algunas prendas de vestir) y $50 \%$ de los adelantos o préstamos, destinado a cubrir fiestas o rituales tales como bautismos, entierros, fiesta del santo personal y ofrendas de día de muertos (de padres, madres, esposas, hijos, suegros) incluyendo

\footnotetext{
42 Ibídem, fols. $149 \mathrm{v}$ y 171.

43 Ibídem, fol. 160.

44 "Memoria de los esclavos y esclavas que se visten cada año y las que sirven en la casa de arriba", AGN, Concurso de Calvo, vol. I, exp.10, fols. 255-255v.
} 
mortajas, el cura y los cantores. Esto quiere decir que, si bien la deuda servía a la empresa para retener mano de obra, los trabajadores utilizaban un $80 \%$ para satisfacer necesidades sociales y culturales ya sea dentro del ingenio o, quizás, de los lugares de donde eran originarios, tales como el financiamiento que se les daba para ir a la novena en Tecpancingo, la Semana Santa en Atlixco o Puebla o "la fiesta de Cuilocán. Esto remite inevitablemente al tema de la introducción de mecanismos de coerción que apelaban a las sensibilidades más profundas, pero también a la eficacia de las nuevas prácticas culturales como presiones sociales, ya fuese por el imperativo de sobrevivir económicamente como también por seguir perteneciendo a una comunidad o lograr el ingreso a una de ellas dentro de un contexto de desestructuraciónestructuración permanente en la sociedad posconquista.

En el rubro alimentos es interesante observar que junto a los préstamos para sembrar maíz o fanegas, estos también se utilicen para complementar la dieta, con otros que no están en la ración, tales como tomates y chile. En vestuario se pide para naguas, zapatos, pañuelos y calzones, pero también hay algunos que clasifiqué como "vestuario de estatus", porque era para jubones, calzas, gabanes, capotes, corazas u otros que denotaban diferencia, por cuanto se daba a los mayordomos o gente de confianza. Otras prendas que denotaban estatus eran las espuelas, sillas de montar, caballos, frenos y fustes. Algunas deudas que tenían algunos trabajadores con otros cubrían la compra de sillas, hechuras de vestuario o hábitos de cofradías: a Joseph de la Rea se le dieron 12 pesos y cuatro reales para un hábito de San Francisco que había comprado a Diego Méndez ${ }^{45}$.

Estos gastos eran fomentados por el ingenio. En este sentido la deuda responde a un control del patrón de consumo y a una transformación del mismo de acuerdo con la creación de nuevas necesidades, como se ve poniendo atención en lo que se denomina "repartimiento anual". Este contemplaba un aguinaldo en dinero y vestuario de "lujo" como medias de Bretaña o de Toluca, privilegios como el tabaco, que no se daba a todos, sino principalmente a esclavos en puestos de administración y a los trabajadores clave o esenciales, como carpinteros y herreros. Este fomento de la diferenciación interna de los trabajadores también servía para crear más obligaciones y lealtades hacia el ingenio en los trabajadores indispensables como el grupo de "los que comen a la mesa del ingenio y beben chocolate a mañana y tarde”, entre los que estaban el administrador Diego Méndez, el maestro de azúcar, los dos carpinteros, los dos herreros, el ingeniero, el cirujano y el capellán ${ }^{46}$. El nivel de endeudamiento era más alto mientras mayor fuera el cargo, aunque se tratase de un esclavo. En ellos las necesidades eran más sofisticadas y se diversificaban hacia otros ámbitos menos

\footnotetext{
45 "Memoria del gasto ordinario desde $1^{\circ}$ de enero desde 1694 hasta diciembre", AGN, Concurso de Calvo, vol. I, exp. 5, fol. 164v.

46 "Memoria de los que comen a la mesa del ingenio y beben chocolate a mañana y tarde", AGN, Concurso de Calvo, vol. I, fol. 251v.
} 
tradicionales. Por ejemplo, Francisco de Herrera, mayordomo de la estancia de Nopala, pide para “aliñar su arcabuz” y comprar un coleto, o Joseph López, mayordomo del rancho del Rosario, que pide para pagar "el maestro de su hijo"47.

Lo interesante es ver el endeudamiento como medio de satisfacer necesidades sociales y culturales, de la no tan simple vida social y comunitaria y del consumo de bienes no alimentarios. Esto obliga a pensar en el ingenio azucarero como un espacio económico en sí mismo, dentro del cual circulaban bienes y moneda; un mercado cerrado que cubría desde las necesidades más básicas hasta aquellas imprescindibles para el trabajador, como curarse con un indio y no con el cirujano del ingenio: "En dicho día un peso a Sebastián de la Cruz que pidió para pagarle a un indio que le debía una cura que le había hecho"48. Y un peso o dos son significativos dentro de salarios que van de los tres pesos a los 10. Entonces ¿cuánto estaba dispuesto a pedir prestado y a deber un trabajador? Siendo la hacienda azucarera un espacio de circulación de especies y moneda, la rentabilidad de la mano de obra también consideraba el control del gasto y el consumo de los trabajadores, de manera que regresase el capital invertido en ellos. De hecho, la principal causal de expulsión o despido tenía que ver con violaciones a esta norma: "Y pagué a dicho peón albañil nueve días que tenía en el libro de raya y se despidió por mandado del Señor por haberle comprado una gabardina a un esclavo”49.

La muestra con la que se cuenta solo permite esbozar estas tendencias. Un estudio estadístico de más larga duración daría pistas y datos quizás insospechados para pensar la lógica de la actividad económica en las empresas coloniales así como las complejas relaciones de la economía con los planos de la cultura y las mentalidades que incidirían en esa lógica como invisibles e indispensables hilos de los que pende la vida.

\footnotetext{
47 "Memoria del gasto ordinario desde $1^{\circ}$ de enero desde 1694 hasta diciembre", AGN, Concurso de Calvo, vol. I, exp. 5, fols. 166v y 172.

48 Ibídem, fol. 207v.

49 Ibídem, fol. 144.
} 


\section{Anexo 1}

\section{Tabla 1}

Salarios de cuadrilla de indios de Cholula traídos para trabajar en las cañas por Juan Joseph de Avilés (02-09-1694).

\begin{tabular}{|l|l|l|}
\hline \multicolumn{1}{|c|}{ Trabajador } & $\begin{array}{c}\text { Tiempo trabajado } \\
\text { (días) }\end{array}$ & \multicolumn{1}{|c|}{$\begin{array}{c}\text { Salario total recibido } \\
\text { (en pesos y reales) }\end{array}$} \\
\hline Joseph Romero, capitán & 25 & $6 \mathrm{p} 6 \mathrm{r}$ \\
\hline Diego Romero & 25 & $6 \mathrm{p} 6 \mathrm{r}$ \\
\hline Juan Romero & 26 & $6 \mathrm{p} 4 \mathrm{r}$ \\
\hline Diego de Santiago & 16 & $4 \mathrm{p}$ \\
\hline Juan Gabriel & 15 & $4 \mathrm{p} 2 \mathrm{r}$ \\
\hline Pascual Quautla & 18 & $4 \mathrm{p} 4 \mathrm{r}$ \\
\hline Joseph de la Cruz & 27 & $6 \mathrm{p} 6 \mathrm{r}$ \\
\hline Juan Alonso & 22 & $5 \mathrm{p} 6 \mathrm{r}$ \\
\hline Juan Teguisotl & 27 & $6 \mathrm{p} 6 \mathrm{r}$ \\
\hline Pascual de la Cruz & 24 & $6 \mathrm{p}$ \\
\hline Diego Palma & 15 & $3 \mathrm{p} 6 \mathrm{r}$ \\
\hline Juan Avendaño & 24 & $6 \mathrm{p}$ \\
\hline Joseph Lama & 14 & $3 \mathrm{p} 4 \mathrm{r}$ \\
\hline Juan Tepo & 18 & $4 \mathrm{p} 4 \mathrm{r}$ \\
\hline Juan Lucas & 25 & $6 \mathrm{p} 2 \mathrm{r}$ \\
\hline Francisco Quautecotl & 15 & $4 \mathrm{p} 2$ \\
\hline Felipe de Santiago & 5 & $1 \mathrm{p} 2 \mathrm{r}$ \\
\hline Juan Asencio & 12 & $3 \mathrm{p}$ \\
\hline Pablo Antonio & 16 & $4 \mathrm{p}$ \\
\hline Bartolomé Christóbal & 12 & $3 \mathrm{p}$ \\
\hline Miguel de la Cruz & 13 & $3 \mathrm{p} 2 \mathrm{r}$ \\
\hline Pedro Solís & 25 & $6 \mathrm{p} 6 \mathrm{r}$ \\
\hline Ignacio Romero & 27 & $3 \mathrm{p} 3 \mathrm{r}$ (pagado a real cada día) \\
\hline Juan Asencio & 27 & $3 \mathrm{p} 3 \mathrm{r}$ (pagado a real) \\
\hline Pedro de Chile & 26 & $6 \mathrm{p} 4 \mathrm{r}$ \\
\hline Felipe Soto & 56 & $6 \mathrm{p} 4 \mathrm{r}$ \\
\hline Diego Cocotl & 8 & $1 \mathrm{p} 2 \mathrm{r}$ \\
\hline Juan Andrés & 5 & $2 \mathrm{p}$ \\
\hline Antonio Jacobo & $1 \mathrm{p} 2 \mathrm{r}$ \\
\hline Diego Ham & & \\
\hline
\end{tabular}




\begin{tabular}{|c|c|c|}
\hline Trabajador & $\begin{array}{c}\text { Tiempo trabajado } \\
\text { (días) }\end{array}$ & $\begin{array}{l}\text { Salario total recibido } \\
\text { (en pesos y reales) }\end{array}$ \\
\hline Felipe de la Cruz & 13 & $3 p 2 r$ \\
\hline Sebastián de la Puente & 14 & $3 p 4 r$ \\
\hline Felipe Chacal & 15 & $3 p 6 r$ \\
\hline Juan Tepos & 17 & $4 \mathrm{p} 2 \mathrm{r}$ \\
\hline Felipe de la Puente & 17 & $4 \mathrm{p} 2 \mathrm{r}$ \\
\hline Lucas de la Puente & 17 & 4p2r (pagados a real por día) \\
\hline María Hacate & 22 & $5 \mathrm{p} 4 \mathrm{r}$ \\
\hline Pascuala Hacate & 26 & $6 \mathrm{p} 4 \mathrm{r}$ \\
\hline Pascuala María & 35 & 8p6r \\
\hline Juan Lucas & 17 & $4 \mathrm{p} 2 \mathrm{r}$ \\
\hline Juan Andrés & 17 & $4 \mathrm{p} 2 \mathrm{r}$ \\
\hline Gabriel de la Cruz & 6 & $1 \mathrm{p} 4 \mathrm{r}$ \\
\hline Lucas Marín & 15 & $3 p 6 r$ \\
\hline Francisco Matheo & 15 & $3 p 6 r$ \\
\hline Diego de la Cruz & 17 & 2p1r (pagado a real por día) \\
\hline Miguel de la Cruz & 17 & $2 \mathrm{p} 1 \mathrm{r}$ \\
\hline Francisco Ramos & 17 & $4 \mathrm{p} 2 \mathrm{r}$ \\
\hline Bartolomé Tequiloque & 17 & $4 \mathrm{p} 2 \mathrm{r}$ \\
\hline Calisto Quatlazotl & 16 & $4 \mathrm{p}$ \\
\hline Francisco Poleto & 13 & $3 \mathrm{p} 2 \mathrm{r}$ \\
\hline Juan Totole & 16 & $4 \mathrm{p}$ \\
\hline Jacova María & 19 & $4 \mathrm{p} 6 \mathrm{r}$ \\
\hline Juan Ortiz & 14 & $3 \mathrm{p} 4 \mathrm{r}$ \\
\hline Lucas Quimichi & 6 & $1 \mathrm{p} 4 \mathrm{r}$ \\
\hline Diego Coyote & 6 & $1 \mathrm{p} 4 \mathrm{r}$ \\
\hline Juan Mathias & 6 & $1 \mathrm{p} 4 \mathrm{r}$ \\
\hline Michaela Pascuala & 2 & $4 \mathrm{r}$ \\
\hline Joseph Avilés & & 30p3r \\
\hline Total, 59 indios & $\begin{array}{l}\text { Promedio de días } \\
\text { trabajados: } 16,5\end{array}$ & $273 p 5 r$ \\
\hline
\end{tabular}

Fuente: "Memoria de los Indios de Cholula”, AGN (México), Concurso de Calvo, vol. 1, exp.12, fols. $283-285$. 
Tabla 2

Cuadrillas empleadas en el trabajo de la caña (1694)

\begin{tabular}{|c|c|c|c|c|}
\hline $\begin{array}{c}\text { PUEBLO O } \\
\text { CAPITÁN }\end{array}$ & $\begin{array}{l}\text { NÚMERO DE } \\
\text { INDIOS }\end{array}$ & $\begin{array}{l}\text { SALARIO } \\
\text { GRUPAL } \\
\text { (en pesos y } \\
\text { reales) }\end{array}$ & MES & $\begin{array}{c}\text { FUNCIÓN } \\
\mathbf{R}=\text { indios regadores } \\
\mathbf{I}=\text { indios en labores } \\
\text { agrícolas }\end{array}$ \\
\hline $\begin{array}{l}\text { Pueblo de } \\
\text { Izúcar: cap. } \\
\text { Sebastián } \\
\text { Coyote }\end{array}$ & $\begin{array}{l}226 \\
0 \\
0 \\
518 \text { y medio } \\
575 \\
\\
719 \\
\\
695 \text { y medio } \\
566 \\
479 \\
580 \\
280 \\
411\end{array}$ & $\begin{array}{l}56 \mathrm{p} \\
0 \\
0 \\
129 \mathrm{p} 5 \mathrm{r} \\
143 \mathrm{p} \\
\\
191 \mathrm{p} 1 \mathrm{r} \\
\\
177 \mathrm{p} 1 \mathrm{r} \\
141 \mathrm{p} \\
119 \mathrm{p} 6 \mathrm{r} \\
151 \mathrm{p} 4 \mathrm{r} \\
52 \mathrm{p} \\
103 \mathrm{p} 2 \mathrm{r}\end{array}$ & $\begin{array}{l}\text { Enero } \\
\text { Febrero } \\
\text { Marzo } \\
\text { Abril* } \\
\text { Mayo } \\
\\
\text { Junio } \\
\\
\text { Julio } \\
\text { Agosto } \\
\text { Septiembre } \\
\text { Octubre } \\
\text { Noviembre } \\
\text { Diciembre }\end{array}$ & $\begin{array}{l}\text { I (sembrando) } \\
\text { I } \\
\text { I } \\
\text { I } \\
\text { I (En una partida de } 80 \\
\text { indios, Coyote es } \\
\text { nombrado como capitán } \\
\text { de Izúcar) } \\
\text { I (En el campo, Coyote } \\
\text { sigue siendo nombrado } \\
\text { como capitán de Izúcar) } \\
\text { I } \\
\text { I (Sigue como capitán de } \\
\text { Izúcar) } \\
\text { I } \\
\text { I (120 indios para el } \\
\text { xaguey) }\end{array}$ \\
\hline $\begin{array}{l}\text { Pueblo de } \\
\text { Izúcar- } \\
\text { Ayotlam: cap. } \\
\text { Juan Agustín }\end{array}$ & $\begin{array}{l}738 \text { y medio } \\
557 \\
654 \\
848 \text { y medio } \\
1029 \text { y medio } \\
730 \\
1097\end{array}$ & $\begin{array}{l}187 \mathrm{p} 1 \mathrm{r} \\
139 \mathrm{p} \\
163 \mathrm{p} 6 \mathrm{r} \\
212 \mathrm{p} 2 \mathrm{r} \\
280 \mathrm{p} 4 \mathrm{r} 1 / 2 \\
182 \mathrm{p} 5 \mathrm{r} \\
273 \mathrm{p} 3 \mathrm{r}\end{array}$ & $\begin{array}{l}\text { Julio } \\
\text { Agosto } \\
\text { Septiembre } \\
\text { Octubre } \\
\text { Noviembre } \\
\text { Diciembre }\end{array}$ & $\begin{array}{l}\text { I (En el campo y ocho } \\
\text { macheteros) } \\
\text { I } \\
\text { I } \\
\text { I (Para la hacienda del } \\
\text { Rosario: 4) } \\
\text { (En una partida de } 104 \\
\text { indios, se dice que Juan es } \\
\text { capitán de Ayotlam) } \\
\text { I (En una partida de } 80 \\
\text { indios, Juan vuelve a ser } \\
\text { asignado al pueblo de } \\
\text { Ayutla) } \\
\text { I (En el campo, Juan sigue } \\
\text { siendo nombrado como } \\
\text { capitán de Ayotlam) } \\
\text { I } \\
\text { I } \\
\text { I } \\
\text { I } \\
\text { I } \\
\text { I }\end{array}$ \\
\hline
\end{tabular}




\begin{tabular}{|c|c|c|c|c|}
\hline $\begin{array}{c}\text { PUEBLO O } \\
\text { CAPITÁN }\end{array}$ & $\begin{array}{l}\text { NÚMERO DE } \\
\text { INDIOS }\end{array}$ & $\begin{array}{c}\text { SALARIO } \\
\text { GRUPAL } \\
\text { (en pesos y } \\
\text { reales) } \\
\end{array}$ & MES & $\begin{array}{c}\text { FUNCIÓN } \\
\mathbf{R}=\text { indios regadores } \\
\mathbf{I}=\text { indios en labores } \\
\text { agrícolas }\end{array}$ \\
\hline $\begin{array}{l}\text { Pagados por } \\
\text { el mayordomo } \\
\text { del ingenio }\end{array}$ & $\begin{array}{l}411 \\
\text { (19 capitanes) } \\
711 \\
\text { ( } 30 \text { capitanes) } \\
3164 \text { y medio } \\
(23 \mathrm{c}) \\
723 \\
\text { ( } 31 \text { capitanes) } \\
638 \\
\text { ( } 25 \text { capitanes) } \\
459 \text { y medio } \\
(30 \text { c) } \\
396 \text { y medio } \\
\text { (25 c) } \\
249\} \\
\text { (22 capitanes) } \\
456 \\
(32 \text { capitanes) } \\
439 \text { ( } 30) \\
471 \\
(33 \text { capitanes) } \\
547 \\
\text { (35 capitanes) }\end{array}$ & $\begin{array}{l}106 \mathrm{p} \\
175 \mathrm{p} 2 \mathrm{r} \\
791 \mathrm{p} 3 \mathrm{r} \\
178 \mathrm{p} 2 \mathrm{r} \\
150 \mathrm{p} 3 \mathrm{r} 1 / 2 \\
110 \mathrm{p} 3 \mathrm{r} \\
98 \mathrm{p} 5 \mathrm{r} 1 / 2 \\
63 \mathrm{p} 1 / 2 \mathrm{r} \\
\\
107 \mathrm{p} 3 \mathrm{r} 1 / 2 \\
103 \mathrm{p} 4 \mathrm{r} \\
132 \mathrm{p} 2 \mathrm{r} 1 / 2 \\
129 \mathrm{p} 5 \mathrm{r}\end{array}$ & $\begin{array}{l}\text { Enero } \\
\text { Febrero } \\
\text { Marzo } \\
\text { Abril } \\
\text { Mayo } \\
\text { Junio } \\
\text { Julio } \\
\text { Agosto } \\
\text { Septiembre } \\
\text { Octubre } \\
\text { Noviembre } \\
\text { Diciembre }\end{array}$ & $\begin{array}{l}\mathrm{R} \\
\mathrm{R} \\
\mathrm{R} \\
\mathrm{R} \\
\mathrm{R} \text { (Entraron 14 en la } \\
\text { cuenta de Sebastián } \\
\text { Coyote) } \\
\mathrm{R} \\
\mathrm{R} \\
\mathrm{R} \text { (En hacer tareas se } \\
\text { ocuparon 16 y medio) } \\
\mathrm{R} \text { (En la soca estaban 27) } \\
\mathrm{R}\end{array}$ \\
\hline $\begin{array}{l}\text { Santa Ana: } \\
\text { cap. Joseph } \\
\text { Diego }\end{array}$ & $\begin{array}{l}?(453 \\
\text { tareas**) } \\
¿ ?(345 \text { tareas }) \\
¿ ?(431 \text { tareas }) \\
i ?(347 \text { tareas }) \\
¿ ?(570 \text { tareas }) \\
¿ ?(384 \text { tareas }) \\
¿ ?(454 \text { tareas }) \\
¿ ?(509 \text { tareas }) \\
¿ ?(564 \text { tareas }) \\
¿ ?(597 \text { y } \\
\text { media) } \\
¿ ?(526 \text { tareas }) \\
¿ ?(241 \text { tareas })\end{array}$ & $\begin{array}{l}112 \mathrm{p} 1 \mathrm{r} \\
86 \mathrm{p} 2 \mathrm{r} \\
107 \mathrm{p} 6 \mathrm{r} \\
86 \mathrm{p} 4 \mathrm{r} \\
145 \mathrm{p} \\
95 \mathrm{p} 5 \mathrm{r} \\
113 \mathrm{p} 1 \mathrm{r} \\
127 \mathrm{p} 2 \mathrm{r} \\
141 \mathrm{p} 4 \mathrm{r} \\
149 \mathrm{p} \\
151 \mathrm{p} 6 \mathrm{r} \\
58 \mathrm{p} 2 \mathrm{r}\end{array}$ & $\begin{array}{l}\text { Enero } \\
\text { Febrero } \\
\text { Marzo } \\
\text { Abril } \\
\text { Mayo } \\
\text { Junio } \\
\text { Julio } \\
\text { Agosto } \\
\text { Septiembre } \\
\text { Octubre } \\
\text { Noviembre } \\
\text { Diciembre }\end{array}$ & $\begin{array}{l}\text { I (Cortar la caña) } \\
\text { I } \\
\text { I (Cortar leña) } \\
\text { I } \\
\text { I } \\
\text { I } \\
\text { I (Cortar leña, } 87 \text { para las } \\
\text { cañas) } \\
\text { I } \\
\text { I } \\
\text { I } \\
\text { I } \\
\text { I }\end{array}$ \\
\hline
\end{tabular}




\begin{tabular}{|c|c|c|c|c|}
\hline $\begin{array}{c}\text { PUEBLO O } \\
\text { CAPITÁN }\end{array}$ & $\begin{array}{l}\text { NÚMERO DE } \\
\text { INDIOS }\end{array}$ & $\begin{array}{l}\text { SALARIO } \\
\text { GRUPAL } \\
\text { (en pesos y } \\
\text { reales) }\end{array}$ & MES & $\begin{array}{c}\text { FUNCIÓN } \\
\mathbf{R}=\text { indios regadores } \\
\mathbf{I}=\text { indios en labores } \\
\text { agrícolas }\end{array}$ \\
\hline $\begin{array}{l}\text { Pueblo de } \\
\text { Cuilocam: } \\
\text { cap. Baltazar } \\
\text { Francisco }\end{array}$ & $\begin{array}{l}?(304 \text { tareas }) \\
i ?(332 \text { tareas }) \\
i ?(233 \text { tareas }) \\
i ?(132 \text { tareas }) \\
i ?(190 \text { tareas) } \\
i ?(147 \text { tareas) } \\
i ?(178 \text { tareas) } \\
i ?(258 \text { tareas) } \\
i ?(162 \text { tareas) } \\
i ?(347 \text { tareas) } \\
i ?(329 \text { tareas }) \\
i ?(180 \text { tareas })\end{array}$ & $\begin{array}{l}76 \mathrm{p} \\
83 \mathrm{p} \\
68 \mathrm{p} 2 \mathrm{r} \\
33 \mathrm{p} \\
50 \mathrm{p} 4 \mathrm{r} \\
36 \mathrm{p} 6 \mathrm{r} \\
38 \mathrm{p} 4 \mathrm{r} \\
64 \mathrm{p} 4 \mathrm{r} \\
40 \mathrm{p} 4 \mathrm{r} \\
86 \mathrm{p} 6 \mathrm{r} \\
82 \mathrm{p} \\
45 \mathrm{p} \\
\end{array}$ & $\begin{array}{l}\text { Enero } \\
\text { Febrero } \\
\text { Marzo } \\
\text { Abril } \\
\text { Mayo } \\
\text { Junio } \\
\text { Julio } \\
\text { Agosto } \\
\text { Septiembre } \\
\text { Octubre } \\
\text { Noviembre } \\
\text { Diciembre }\end{array}$ & $\begin{array}{l}\text { I } \\
\text { I } \\
\text { I (Cortando leña) } \\
\text { I (Cortando leña) } \\
\text { I } \\
\text { I } \\
\text { I } \\
\text { I } \\
\text { I } \\
\text { I } \\
\text { I } \\
\text { I }\end{array}$ \\
\hline $\begin{array}{l}\text { Pueblo de } \\
\text { Azala: cap. } \\
\text { Maldonado }\end{array}$ & $\begin{array}{l}123 \text { y medio } \\
0 \\
0 \\
172 \\
87 \\
80 \\
78 \\
80\end{array}$ & $\begin{array}{l}30 \mathrm{p} 4 \mathrm{r} \\
0 \\
0 \\
40 \mathrm{p} 4 \mathrm{r} \\
21 \mathrm{p} 6 \mathrm{r} \\
20 \mathrm{p} \\
19 \mathrm{p} 5 \mathrm{r} \\
20 \mathrm{p}\end{array}$ & $\begin{array}{l}\text { Enero } \\
\text { Febrero } \\
\text { Marzo } \\
\text { Abril } \\
\text { Mayo } \\
\text { Junio } \\
\text { Julio } \\
\text { Diciembre }\end{array}$ & $\begin{array}{l}\text { I (Dando tierra a soca } 41 \\
\text { y } 30 \text { en el campo)*** } \\
\text { I } \\
\text { I } \\
\text { I } \\
\text { I (En la primera escarda) } \\
\text { I } \\
\text { I } \\
\text { I } \\
\text { I }\end{array}$ \\
\hline $\begin{array}{l}\text { Capitanes del } \\
\text { campo: Juan } \\
\text { Agustín, } \\
\text { Maldonado, } \\
\text { Coyote }\end{array}$ & $\begin{array}{l}197 \\
118\end{array}$ & $\begin{array}{l}58 \mathrm{p} 7 \mathrm{r} \\
29 \mathrm{p} 4 \mathrm{r}\end{array}$ & $\begin{array}{l}\text { Enero } \\
\text { abril }\end{array}$ & $\begin{array}{l}\text { I (Trabajando en el } \\
\text { campo) } \\
\text { I (Solo se menciona a } \\
\text { Juan y a Coyote) }\end{array}$ \\
\hline $\begin{array}{l}\text { Indios } \\
\text { Cholultecos }\end{array}$ & $\begin{array}{l}40 \\
23 \\
39 \\
12 \text { y medio }\end{array}$ & $\begin{array}{l}10 \mathrm{p} 5 \mathrm{r} \\
5 \mathrm{p} 6 \mathrm{r} \\
9 \mathrm{p} 3 \mathrm{r} \\
3 \mathrm{p}\end{array}$ & $\begin{array}{l}\text { Septiembre } \\
\text { (dgo 26) } \\
\text { Octubre } \\
\text { Noviembre } \\
\text { Diciembre }\end{array}$ & $\begin{array}{l}\text { I (Trabajaron un día, } \\
\text { incluyendo a cuatro indias } \\
\text { por un peso. A los indios } \\
\text { se les pagó 9p3r) } \\
\text { I (Una cuadrilla, "que } \\
\text { trabajaron que pidieron se } \\
\text { les diere") } \\
\text { I (Traídos } 11 \text { por Joseph } \\
\text { de Avilés, trabajando en } \\
\text { el Xaguey) } \\
\text { I }\end{array}$ \\
\hline $\begin{array}{l}\text { Atlixco: } \\
\text { traídos por } \\
\text { Joseph de } \\
\text { Avilés }\end{array}$ & ¿35 y medio? & $8 \mathrm{p} 7 \mathrm{r}$ & febrero & I (Trabajo en el Ingenio) \\
\hline
\end{tabular}




\begin{tabular}{|c|c|c|c|c|}
\hline $\begin{array}{c}\text { PUEBLO O } \\
\text { CAPITÁN }\end{array}$ & $\begin{array}{l}\text { NÚMERO DE } \\
\text { INDIOS }\end{array}$ & $\begin{array}{c}\text { SALARIO } \\
\text { GRUPAL } \\
\text { (en pesos y } \\
\text { reales) }\end{array}$ & MES & $\begin{array}{c}\text { FUNCIÓN } \\
\mathbf{R}=\text { indios regadores } \\
\mathbf{I}=\text { indios en labores } \\
\text { agrícolas }\end{array}$ \\
\hline $\begin{array}{l}\text { Diego de la } \\
\text { Cruz los } \\
\text { contrató, } \\
\text { mayordomo }\end{array}$ & 363 & $\begin{array}{l}7 \mathrm{p} \\
3 \mathrm{p} 6 \mathrm{r} \\
90 \mathrm{p} 2 \mathrm{r}\end{array}$ & $\begin{array}{l}\text { Febrero } \\
\text { Noviembre } \\
\text { Diciembre }\end{array}$ & $\begin{array}{l}\text { I (Sembradores de aquile) } \\
\text { I (Para cortar madera en } \\
\text { Xaltianguez, 6; para cortar } \\
\text { carrizo, 2) } \\
\text { (Para la hacienda el } \\
\text { Rosario y labrar garbanzo, } \\
42 \text { indios, y } 141 \text { para } \\
\text { recoger cosecha en la } \\
\text { misma hacienda, } 80 \text { indios } \\
\text { llevados por Gregorio } \\
\text { Precastegui) }\end{array}$ \\
\hline $\begin{array}{l}\text { Francisco de } \\
\text { Herrera: } \\
\text { mayordomo } \\
\text { de Nopala }\end{array}$ & $\begin{array}{l}40 \\
160 \\
162 \\
155\end{array}$ & $\begin{array}{l}10 p \\
40 p \\
42 p\end{array}$ & $\begin{array}{l}\text { Junio } \\
\text { Julio } \\
\text { Agosto }\end{array}$ & $\begin{array}{l}\text { I (Sembradores de maíz) } \\
\text { I (Limpieza del maíz } \\
\text { temporal) } \\
\text { I (Limpieza del maíz } \\
\text { temporal y 12p pagados } \\
\text { en dos vacas a los indios } \\
\text { de Azala) } \\
\text { I (Para limpiar temporal y } \\
\text { sembrar fríjol, } 40, \text { y } 40 \\
\text { abriendo la acequia para } \\
\text { regar el temporal y } 35 \\
\text { para recoger el último } \\
\text { aquile) } \\
\text { I (Para limpiar el fríjol, } \\
21, \text { y } 40 \text { para cortar } \\
\text { alaquale de las milpas y } \\
\text { hacer la acequia para } \\
\text { regar el fríjol) }\end{array}$ \\
\hline
\end{tabular}




\begin{tabular}{|c|c|c|c|c|}
\hline $\begin{array}{c}\text { PUEBLO O } \\
\text { CAPITÁN }\end{array}$ & $\begin{array}{l}\text { NÚMERO DE } \\
\text { INDIOS }\end{array}$ & $\begin{array}{c}\text { SALARIO } \\
\text { GRUPAL } \\
\text { (en pesos y } \\
\text { reales) }\end{array}$ & MES & $\begin{array}{c}\text { FUNCIÓN } \\
\mathbf{R}=\text { indios regadores } \\
\mathbf{I}=\text { indios en labores } \\
\text { agrícolas }\end{array}$ \\
\hline & 574 & $143 \mathrm{p} 7 \mathrm{r}$ & Diciembre & $\begin{array}{l}\text { I (Abriendo la cerca del } \\
\text { garbanzo, 20, y } 8 \\
\text { limpiando el barbecho, } 4 \\
\text { cortando zacate, } 6 \text { traídos } \\
\text { por Marcos Caraveos para } \\
\text { traer los aradores de los } \\
\text { gañanes) } \\
\text { I (Para la cosecha de } \\
\text { maíz, } 40 \text { para hacer sacos } \\
\text { con el maíz cosechado, } 20 \\
\text { comienzan a cosechar el } \\
\text { fríjol, } 20 \text { cosechan fríjol y } \\
\text { cosechan el melonar, } 20 \\
\text { amontonan maíz) }\end{array}$ \\
\hline
\end{tabular}

Fuente: “Cuenta Nueva desde hoy $1^{\circ}$ de enero de 1694”, AGN (México), Concurso de Calvo, vol. 1, exp.5, fols. 142-213, y "Memoria del gasto ordinario que se ha hecho en este ingenio de San Nicolás Tolentino desde $1^{\circ}$ de enero de 1694 hasta fin de diciembre del, por sus días y meses”, Ibídem., exp.7, fols. 216-257v y 240v.

* En este mes hay cuatro días sin trabajo que correspondieron al 9-10-11, y 12 por Semana Santa.

** Tarea: Era la superficie de una suerte que se utilizaba para contabilizar las diferentes labores agrícolas, podía ser de 10 varas cuadradas.

*** Soca: Es el retoño que brota por primera vez la caña de azúcar. 


\section{Bibliografía}

\section{Fuentes primarias}

Archivo General de la Nación, México.

\section{Fuentes Secundarias}

Assadourian, Carlos Sempat y Andrea Martínez Baracs. "Representación de la ciudad de Tlaxcala sobre la condición de los gañanes, 1767”. En Tlaxcala, textos de su historia. Siglos XVII-XVIII, vol. 7: 225-237. México: Conaculta; Gobierno de Tlaxcala, 1991.

Barret, Ward. La hacienda azucarera de los marqueses del valle (1535-1910). México: Siglo XXI, 1977.

y Stuart B. Schwartz. “Comparación entre dos economías azucareras coloniales: Morelos, México y Bahía, Brasil”. En Haciendas, latifundios y plantaciones en América Latina, coord. Enrique Florescano, 532-572. México: Siglo XXI, 1975.

Bazant, Jan. “El trabajo y los trabajadores en la hacienda de Atlocomulco”. En El trabajo y los trabajadores en la historia de México, comp. Elsa Frost, 378-390. México: El Colegio de México; University of Arizona Press, 1979.

Crespo, Horacio. Historia del azúcar en México. 2 vols. México: Fondo de Cultura Económica; Azúcar S. A. de C. V., 1980-1990.

González Sánchez, Isabel. “La retención por deudas y los traslados de trabajadores tlaquehuales o alquilados en las haciendas como sustitución de los repartimientos de indios durante el siglo XVIII”. Anales del INAH (México), tomo XIX, 48 (1967): 241-250.

- Los trabajadores alquilados de Tlaxcala para las haciendas foráneas. Siglo XVIII. Cuadernos de Trabajo del Departamento de Investigaciones Históricas. No. 13. México: INAH, 1976.

Kula, Witold. Teoría económica del sistema feudal. 2 ed. México: Siglo XXI, 1979.

Mellafe Rojas, Rolando. “Latifundio y poder rural en Chile de los siglos XVII y XVIII”. En Historia social de Chile y América. Sugerencias y aproximaciones, 88-89. Santiago: Editorial Universitaria, 1986. 
Nickel, Herbert. Relaciones de trabajo en las haciendas de Puebla y Tlaxcala (1740-1914). Cuatro análisis sobre reclutamiento, peonaje y remuneración. México: Universidad Iberoamericana, 1987.

Paredes Martínez, Carlos. El impacto de la conquista y colonización española en la antigua Coatlalpan (Izúcar, Puebla) en el primer siglo colonial. Cuadernos de la Casa Chata. México: Ciesas, 1991.

. La región de Atlixco, Huaquechula y Tochimilco. La sociedad y la agricultura en el siglo XVI. México: Fondo de Cultura Económica; Ciesas, 1991.

Scharrer Tamm, Beatriz. "Trabajadores y cambios tecnológicos en los ingenios (siglos XVII-XVIII). En Trabajo y sociedad en la historia de México, siglos XVI-XVIII, Gloria Artís Espriu y otros, 149-186. México: Ciesas; SEP, 1992.

- Azúcar y trabajo. Tecnología de los siglos XVII y XVIII en el actual Estado de Morelos. México: Ciesas; Instituto de Cultura de Morelos, 1997.

Verlinden, Charles. "El régimen de trabajo en México: aumento y alcance de la gañanía. Siglo XVII”. En Historia y sociedad en el mundo de habla española. Homenaje a José Miranda. Eds. Bernardo García y otros, 225-246. México: El Colegio de México, 1970.

Wobeser, Gisela von. La formación de la hacienda en la época colonial. El uso de la tierra y el agua. México: UNAM, 1989.

. La hacienda azucarera en la época colonial. México: SEP; UNAM, 1988.

Zavala, Silvio. Fuentes para la historia del trabajo en Nueva España, vol. 0. México: Fondo de Cultura Económica, 1939. 